\title{
MOTIVASI MINUM OBAT PADA PASIEN TUBERKULOSIS PARU DITINJAU DARI DUKUNGAN KELUARGA
}

\section{Motivation To Take Medication In Pulmonary Tubercolusis Patiens Reviewed From Family Support}

\author{
Anggia Budiarti, Maritta Sari \\ Akademi Kesehatan Sapta Bakti Bengkulu \\ Email: AnggiaDjonalisman@gmail.com, marittasari1987@gmail.com
}

\begin{abstract}
Abstrak
Tuberkulosis paru merupakan penyakit infeksi yang menyerang berbagai organ terutama parenkim paru-paru yang disebabkan oleh Mycobacterium tuberculosis dengan gejala yang sangat bervariasi. Di Indonesia adalah negara dengan prevalensi TB ke-3 tertinggi di dunia dan di Provinsi Bengkulu kasus Tuberkulosis paru setiap tahunnya semakin meningkat. Kegagalan pengobatan disebabkan beberapa faktor antara lain (a) Obat : panduan obat tidak adekuat, dosis obat tidak cukup, minum obat tidak teratur/tidak sesuai dengan petunjuk yang diberikan, jangka waktu pengobatan kurang dari semestinya, terjadinya resistensi obat; (b) Drop-out : kekurangan biaya pengobatan, merasa sudah sembuh, malas berobat/kurang motivasi ; (c) Penyakit : lesi paru yang sakit terlalu luas/sakit berat, penyakit lain yang menyertai tuberkulosis seperti diabetes melitus, alkoholisme dan penyakit lain serta adanya gangguan imunologis. Tujuan penelitian ini adalah untuk mengetahui gambaran motivasi minum obat pada pasien tuberkulosis paru ditinjau dari dukungan keluarga. Penelitian ini menggunakan metode deskriptif menggunakan teknik acidental sampling dalam pemilihan sampel. Penelitian ini dilakukan di ruang poliklinik paru rumah sakit umum daerah $\mathrm{M}$. Yunus Bengkulu. Pengumpulan data dilakukan dengan menyebarkan lembar chek list kepada setiap responden yang kemudian dianalisa dengan menggunakan table distribusi, dan diinterprestasikan dalam bentuk narasi. Dari hasil penelitian didapat dukungan keluarga pada pasien tuberkulosisparu dalam minum obat dikategori rendah (63,79\%), dan motivasi tinggi (43 \%).
\end{abstract}

Kata Kunci : Motivasi, Obat, dan Tuberkulosis paru.

\begin{abstract}
Pulmonary tuberculosis is an infectious disease that attacks various organs, especially the lung parenchyma caused by Mycobacterium tuberculosis with highly variable symptoms. In Indonesia it is the country with the third highest prevalence of $T B$ in the world and in Bengkulu Province the number of cases of pulmonary TB increases every year. Treatment failure is caused by several factors, including (a) Medication: inadequate medication guidelines, insufficient drug dosage, irregular / not taking medication according to instructions given, less than appropriate treatment period, drug resistance; (b) Drop-out: lack of medical expenses, feeling healed, lazy to seek treatment / lack of motivation; (c) Diseases: too extensive lung pain / severe illness, other diseases that accompany tuberculosis such as diabetes mellitus, alcoholism and other diseases and immunological disorders. The purpose of this study was to determine the description of motivation to take medication in pulmonary tuberculosis patients in terms of family support. This study uses a descriptive method using accidental sampling techniques in sample recovery. This study was conducted in the pulmonary clinic
\end{abstract}


room of the public hospital in the M. Yunus Bengkulu area. Data collection is done by distributing checklist sheets to each respondent which is then analyzed using a distribution table, and interpreted in narrative form. From the results of the study obtained family support for pulmonary tuberculosis patients in taking medication in the low category (63.79\%), and high motivation (43\%.

\section{Keyword: Motivation, Medication, and Pulmonary Tuberculosis}

\section{PENDAHULUAN}

Di Indonesia tuberkulosisparu merupakan masalah kesehatan baik dari sisi angka kematian (mortalitas), angka kejadian penyakit (morbiditas), maupun diagnosis dan terapinya. Penduduk lebih dari 200 juta orang, Indonesia adalah negara dengan prevalensi TB ke-3 tertinggi di dunia setelah China dan India. Insidensi kasus TB BTA positif sekitar 110/100.000 penduduk. Prevalensi nasional terakhir Tuberkulosis paru diperkirakan 0,24\% dari jumlah penduduk. Tuberkulosis paru merupakan penyakit infeksi yang menyerang parenkim paru-paru yang disebabkan oleh Mycobacterium tuberculosis (Somatri, 2009). Sementara itu, Junaidi (2010) menyebutkan tuberculosis (TB) sebagai suatu infeksi akibat Mycobacterium tuberculosis yang dapat menyerang berbagai organ, terutama paru-paru dengan gejala yang sangat bervariasi.

Kurangnya kepatuhan penderita dalam mengkomsumsi obat Tuberkulosis paru dan upaya untuk menhindari penularan mengakibatkan munculnya jumlah perilaku TB yang cukup besar. Penyakit Tuberkulosis paru mempunyai masa pengobatan yang cukup lama yaitu 68 bulan. Dengan waktu tersebut mengakibatkan penderita mengalami rasa bosan, lupa minum obat, serta berhenti dalam melakukan pengobatan sebelum masa penyembuhan yang dianjurkan selesai. Minum obat Tuberkulosis paru secara tidak teratur dapat mengakibatkan penderita resisten terhadap obat anti tuberculosis (OAT) dan menjadi kasus kronis. Oleh karena itu sangat penting untuk mengawasi proses minum obat serta perkembangan penderita, karena ada kecenderungan penderita berhenti minum obat bila gejala telah hilang. Setelah minum obat biasanya gejala Tuberkulosis paru bisa hilang dalam waktu 2-4 minggu. Untuk mencapai kesembuhan dapat dilihat dari kepatuhan pasien itu sendiri dalam melakukan pengobatan dirumah dan kontrol ulang secara rutin pada unit pelayanan kesehatan.

Dalam rangka menurunkan prevalensi Tuberkulosis paru maka dikembangkan program pemberantasan Tuberkulosis paru dengan pengobatan jangka pendek dimana tujuan jangka pendeknya adalah dicapainya penemuan penderita secara bertahap hingga mencapai $70 \%$. Pengobatan penderita Tuberkulosis paru diberikan dalam dua tahap yaitu tahap intensif dan tahap lanjutan. Pada tahap intensif penderita harus minum Obat Anti Tuberkulosis (OAT) setiap hari sebanyak 8 butir dari 4 jenis OAT selama dua bulan (60 hari). Kemudian akhir bulan kedua di evaluasi berupa pemeriksaan dahak penderita sehingga dapat diketahui BTA dahak penderita telah konversi (dari BTA positif tetap BTA positif). Beberapa penelitian menyebutkan bahwa faktor-faktor resiko terjadinya kegagalan konversi disebabkan oleh beberapa hal, salah satunya adalah kurangnya motivasi pasien dalam melakukan pengobatan (Ridwan dkk, 2016). 
Dalam proses pengobatan penderita Tuberkulosis paru, penderita sangat perlu adanya motivasi dari diri sendiri maupun dorongan keluarga, karena sering kali penderita merasa jenuh dan bosan serta menghentikan pengobatannya. Hal tersebut dapat mempengaruhi motivasi pasien Tuberkulosis paru untuk mentuntaskan pengobatannya.Pengobatan Tuberkulosis paru dapat dilaksanakan secara tuntas diperlukan kerjasama yang baik antara penderita Tuberkulosis paru dan tenaga kesehatan, sehingga tidak akan terjadi resistensi obat. Masalah ini menjadi perhatian utama WHO karena mengancam tidak hanya penderita tuberkulosis paru di negara berkembang tetapi juga para penderita tuberkulosis paru di negara maju.Data objektif dari pengobatan tuberkulosis paru dapat merupakan salah satu penyebab terjadinya resistensi obat (Aditama, 2016).

Kegagalan pengobatan yang terbanyak adalah karena kekurangan biaya pengobatan atau merasa sudah sembuh/kurang motivasi. Kegagalan pengobatan ini dapat mencapai $50 \%$ pada terapi jangka panjang, karena sebagian besar penderita TBC paru adalah golongan kurang mampu sedangkan pengobatan tuberkulosis memerlukan waktu lama dan biaya yang banyak (Soeparman, 2016).Kasus drop out menjadi salah satu kendala keberhasilan program pemberantasan Tuberculosis Paru. Kurangnya tingkat pengetahuan penderita tentang penyakit Tuberculosis paru masih kurang karena kebanyakan sebagian besar yang putus berobat hanya tamatan SD ke bawah (Heryanto, 2012). Serta jarak yang jauh antara rumah dengan pelayanan kesehatan yang membutuhkan waktu lama, transportasinya juga sulit dan mahal (Felly Philipus, 2012).
Pencegahan kegagalan pengobatan ini perlu kerjasama yang baik dari dokter dan tim kesehatan lain serta motivasi pengobatan tuberkulosis paru tersebut terhadap penderita antara lain perlunya dukungan keluarga. Karena keluarga merupakan hal yang sangat mempengaruhi keberhasilan pengobatan serta pemberi motivasi yang baik selain dari dalam diri penderita sendiri. Adanya perhatian dan dukungan keluarga dalam mengawasi dan mengingatkan penderita untuk minum obat dapat meningkatkan derajat kesehatan penderita.

Di Provinsi Bengkulu kasus penderita Tuberkulosis paru setiap tahunnya semakin meningkat dari tahun ke tahun khususnya diPoliklinik Paru RSUD Dr. M. Yunus Bengkulu, pada tahun 2016 jumlah kunjungan penderita Tuberkulosis paru dengan BTA $(+)$, sebanyak 254 orang dengan jumlah kasus baru sebanyak 169 orang, dan Penderita Tuberkulosis paru lainnya dengan jumlah kunjungan 755 orang dengan jumlah kasus baru sebanyak 147 orang. Sedangkan pada tahun 2017 jumlah penderita Tuberkulosis paru dengan BTA $(+)$ pada 9 bulan pengobatan sebanyak 90 orang dengan jumlah kasus baru sebanyak 15 orang dan jumlah penderita Tuberkulosis paru lainnya sebanyak 216 orang dengan jumlah kasus baru sebanyak 41 kasus, pada 3 bulan pengobatan jumlah kunjungan penderita Tuberkulosis paru lainnya sebanyak 250 orang dengan jumlah kasus baru sebanyak 35 orang, dan pada 6 bulan pengobatan penderita Tuberkulosis paru lainnya sebanyak 542 orang dengan jumlah kasus baru sebanyak 98 kasus angka kematian sebanyak 52 orang dengan angka kesembuhan sebesar 2.239 orang dan yang mempunyai efek samping sebanyak 255 
orang serta angka yang menghentikan pengobatan (Drop out) sebanyak 79 orang.

\section{BAHAN DAN METODE}

Penelitian ini dilakukan di poliklinik paru RSUD dr.M.Yunus Bengkulu pada bulan Mei 2018 dengan metode penelitian deskriptif. Tujuan penelitian ini adalah untuk mengetahui gambaran motivasi minum obat pada pasien tuberkulosis paru ditinjau dari dukungan keluarga. Sampel dalam penelitian ini berjumlah 58 orang dengan tehnik pemilihan sampel menggunakan acidental sampling. Tehnik yang digunakan dalam pengumpulan data adalah wawancara dan observasi menggunakan lembar ceklist.

\section{HASIL DAN PEMBAHASAN}

Tabel.1 Distribusi Frekuensi Responden Berdasarkan Motivasi Pasien Minum Obat Pada Pasien Tuberkulosis Paru

\begin{tabular}{ccc}
\hline Motivasi Pasien & Frekuensi (F) & Presentase(\%) \\
\hline Rendah & 10 & 17,2 \\
Tinggi & 48 & 82,8 \\
\hline Jumlah & 58 & 100
\end{tabular}

Tabel.1 dapat dilihat bahwah dari 58 responden, sebagian besar $48(82,8 \%)$ pasien tuberkulosis paru mempunyai motivasi tinggi dalam minum obat.

Tabel. 2 Distribusi Frekuensi Responden Berdasarkan Dukungan Keluarga Pada Pasien TB Paru Dalam Minum Obat

\begin{tabular}{ccc}
\hline $\begin{array}{c}\text { Dukungan Keluarga Pada Pasien TB Paru Dalam } \\
\text { Minum Obat }\end{array}$ & Frekuensi (F) & Presentase(\%) \\
\hline Rendah & 12 & 20,7 \\
Tinggi & 46 & 79,3 \\
\hline Jumlah & 58 & 100 \\
\hline
\end{tabular}

Tabel.2 di atas terlihatbahwadari58 responden, sebagian besar 46 (79,3\%)pasien TB Paru memiliki dukungan keluarga yang tinggi dalam minum obat.

Tabel. 3 Distribusi Frekuensi Gambaran Motivasi Minum Obat Pada Pasien TB Paru Ditinjau Dari Dukungan Keluarga

\begin{tabular}{cccccccc}
\hline \multirow{2}{*}{ Dukungan keluarga } & \multicolumn{3}{c}{ Motivasi } & \multicolumn{3}{c}{ Jumlah } \\
\cline { 2 - 5 } & Rendah & \multicolumn{2}{c}{ Tinggi } & & F \\
\cline { 2 - 6 } & $\mathrm{F}$ & $\%$ & $\mathrm{~F}$ & $\%$ & & $\%$ \\
\hline Rendah & 6 & 60 & 4 & 40 & 10 & 100 \\
Tinggi & 6 & 12,5 & 42 & 87,5 & 48 & 100 \\
\hline Jumlah & 12 & 56 & 46 & 44 & 58 & 100 \\
\hline
\end{tabular}

Berdasarkan tabel.3 dapat dilihat bahwa dari 10 orang pasien TB Paru yang memperoleh motivasi rendah, hampir seluruhnya memiliki motivasi dalam minum obat TB Paru yang tinggi. Selanjutnya dari 46 pasien TB Paru yang memperoleh dukungan keluarga yang tinggi, sebagian besar 42 (47,5\%) memiliki motivasi tinggi. Berdasarkan hasil penelitian dapat kita lihat pada tabel 1 dimana dari 58 responden $(82,8 \%)$ memiliki motivasi tinggi, dan $(17,2 \%)$ 
memiliki motivasi rendah pada pasien TB paru dalam minum obat.

Motivasi adalah sesuatu yang mendorong, atau pedorong seseorang bertingkah laku untuk mencapai tujuan tertentu. (Mardiani, 2014). Lebih lanjut bahwa motivasi merupakan tenaga penggerak dan kadang-kadang dilakukan dengan menyampingkan hal-hal yang dianggap kurang bermanfaat dalam mencapai tujuan. Dengan motivasi manusia akan lebih cepat dan bersungguh-sungguh dalam melakukan kegiatan. (Heri Purwanto, 2010). Kemudian menurut Tri Rusmi Widayatun (2010) motivasi adalah pendorong seseorang untuk berperilaku beraktivitas dalam mencapai tujuan.

Hal ini sesuai dengan pendapat (Ridwan dkk, 2016), bahwa tingginya motivasi pasien dalam melanjutkan pengobatan karena adanya tujuan yang ingin dicapainya yaitu kesembuhan dari penyakitnya dan karena adanya dukungan atau dorongan dari anggota keluarganya.

Dari tabel 2 diatas dapat kita lihat dimana dari 58 responden sebagian besar $46(79,3 \%)$ pasien memiliki dukungan keluarga tinngi dalam minum obat dan 12 (20,7\%) memiliki dukungan keluarga pada pasien TB paru dalam minum obat.

Dukungan keluarga adalah sikap, tindakan dan penerimaan keluarga terhadap anggotanya. Anggota keluarga

dipandang sebagai bagian yang tidak terpisahkan dalam lingkungan keluarga. Anggota keluarga memandang bahwa orang yang bersifat mendukung selalu siap memberikan pertolongan dan bantuan jika diperlukan (Friedman, 2008). Pada hakekatnya keluarga diharapkan mampu berfungsi untuk mewujudkan proses pengembangan timbal balik rasa cinta dan kasih sayang antara anggota keluarga, antar kerabat, serta antar generasi yang merupakan dasar keluarga yang harmonis (Soetjiningsih, 2006). Hubungan kasih sayang dalam keluarga merupakan suatu rumah tangga yang bahagia. Dalam kehidupan yang diwarnai oleh rasa kasih sayang maka semua pihak dituntut agar memiliki tanggung. Bentuk dukungan keluarga pada pasien penderita TB Paru yang dapat dilakukan oleh keluarga meliputi : Mengawasi anggota keluarga yang sakit untuk menelan obat secara teratur sesuai dengan anjuran petugas kesehat, mengetahui adanya gejala atau efek samping obat dan merujuk penderita kalau perlu, memberikan dukungan terhadap anggota keluarga yang sakit saat minum obat, selalu mengingat pasien untuk minum obat secara teratur, memberikan waktu istirahat kepada anggota keluarga yang sakit minimal 8 jam sehari, olaraga yang teratur di tempat udara yang berudara segar, memeriksakan penderita untuk periksa ulang dahak pada bulan ke 2,5.

\section{SIMPULAN}

Berdasarkanpenelitian dan pembahasan, makadapatdisimpulkansebagaiberikut :

1. Sebagian besar $48(82,8 \%)$ pasien TB Paru mempunyai motivasi tinggi dalam minum obat.

2. Sebagian besar $46(79,3 \%)$ pasien TB Paru memiliki dukungan keluarga yang tinggi dalam minum obat.

3. Dari 12 orang pasien TB Paru yang memperoleh dukungan keluarga rendah, hampir seluruhnya memiliki motivasi dalam minum obat TB Paru yang tinggi. Selanjutnya dari 46 pasien TB Paru yang memperoleh dukungan keluarga yang tinggi, sebagian besar 42 (47,5\%) memiliki motivasi tinggi. 


\section{SARAN}

1. Diharapkankepadapetugaskeperawatanp oliklinikparu agar memberikanpendidikankesehatankepada keluarga pasien TB Paru agar memberi dukungan kepada pasien dalam minum obat agar pengobatan pasien selesai sampai tuntas.

2. Diharapkankepadapihakakademik agar menambahtentangMateri TB Parusehinggamempermudahmahasiswa dalammembuatKaryaTulisIlmiahlebihla njut.

3. Perludilakukanpenelitianlebihlanjuttenta ng hubungan motivasi dalam minum obat pada pasien TB Paru ditinjau dari dukungan keluarga dengan desain kohor tprosfektif.

DAFTAR PUSTAKA

Junaidi,Iskandar. (2010). Penyakit Paru dan Saluran Pernapasan. Jakarta: Buana Ilmu Populer.
Price,Sylvia

Anderson.

(2003).Patofisologi :KonsepKlinis Proses -Proses penyakit, alihbahasa Peter Anugrah, Jakarta : Penerbit Buku Kedokteran EGC.

Soekidjo, Notoatmodjo. (2010). Metode Penelitian Kesehatan, Runeka Cipta. Jakarta.

Somatri, Irman. (2009). Asuhan Keperawatan pada Klien dengan Gangguan pada Sistem Pernapasan. Jakarta: Salemba Medeka.

Selamiharja. (2014). Pemberantasan Tuberculosis, Cermin Dunia Kedokteran. Jakarta: FKUI Jakarta. Tucker,dkk.(1998).

StandartPerawatanPasien. Jakarta : Penerbit Buku Kedokteran EGC.

Zain.

(2010).RencanaAsuhandanDokumen tasiKeperawatan ,edisi 2 , EGC, Jakarta. 